Ballard, M. E., Rattley, K. T., Fleming, W. C., \& Ashley, P. K. (2004). School Aggression and Dispositional Aggression among Middle School Boys. Research in Middle Level Education Online, 27(1). Published by the National Middle School Association (ISSN: 1084-8959). Original copy available online from Research in Middle Level Education:

http://www.amle.org/Publications/RMLEOnline/Articles/Vol27No1Article3/tabid/531/Default.aspx

\title{
School Aggression and Dispositional Aggression among Middle School Boys
}

\author{
Mary E. Ballard, Kelvin T. Rattley, Willie C. Fleming, Pamela Kidder-Ashley
}

\begin{abstract}
We examined the relationship between dispositional (trait) aggression and administrative reports of school aggression among 100 adolescent male participants from an urban middle school. Aggression was fairly common among the sample; 58 boys had a record of school aggression, and many of those were repeat offenders. Our hypothesis that those higher in dispositional aggression would have more records of aggression at school was supported. Dispositional aggression was significantly, positively correlated with verbal and physical aggression at school. Regression analyses indicated that dispositional aggression accounted for a substantial amount of the variance in administrative reports of school aggression. Two other factors, family income and age, accounted for a minimal amount of the variance in school aggression.
\end{abstract}


Aggression is defined as behavior intended to harm another living being, either physically or emotionally (Berkowitz, 1998a; Geen, 1998). School aggression is perpetrated against students or school personnel while at, or traveling to or from, school or school-sponsored events (National School Safety Center, 2000). Aggression is a relatively stable trait, across both time and context (Eron \& Huesmann, 1990). Those who experience more aggressive thoughts and feelings behave more aggressively across contexts (Bushman, 1995; 1996; Canary, Spitzberg, \& Semic, 1998; Carlo \& Roesch, 1998; Dill, Anderson, Anderson, \& Deuser, 1997; Dula \& Ballard, 2003). We examined if adolescent males with higher levels of dispositional (i.e., trait) aggression were more likely to be cited for instances of school aggression.

Aggression is influenced by a complex interaction of factors (e.g., Berkowitz, 1998b; Geen, 1998; Huesmann, 1994). Anderson and Bushman (Anderson \& Bushman, 2001a; 2001b; Anderson \& Dill, 2000) have proposed a social cognitive model, the General Affective Aggression Model (GAAM), to explain the interactive effects of learning, environment variables, and personality on behavior. Anderson and Bushman note that children learn aggressive scripts and schemas from the environment (e.g., parents, media) that may be modeled later. Socialization of morals and empathy, as well as the child's personality, mediate affective responses, arousal, and a variety of automatic and controlled decision-making processes in response to specific situational factors (e.g., an anger-arousing stimulus). Anderson and Bushman suggest that an aggressive personality (i.e., high dispositional aggression) serves as an input variable in this model to affect behavioral aggression. According to the GAAM, dispositional aggression affects the internal state of the person (e.g., cognitions, affect, and arousal), which in turn affects appraisal (e.g., perception of a threat) and behavior (e.g., aggressive response). That is, those with high levels of dispositional aggression have more ready access to aggressive scripts, experience more negative affect, and are more easily aroused. Thus, they are more likely to make aggressive attributions for others' behavior and are at increased risk for behavioral aggression (Anderson \& Bushman, 2001a; 2001b; Anderson \& Dill, 2000).

Individual differences in behavioral aggression manifest in early childhood and predict the likelihood of aggression more than 40 years later (Eron, 1987; Eron \& Huesmann, 1990; Huesmann, Eron, Lefkowitz, \& Walder, 1984; Huesmann, Moise-Titus, Podolski, \& Eron, in press; Loeber \& Hay, 1997). Dispositional aggression, or the individual's daily experience of aggressive and hostile cognitions and feelings, is viewed as a relatively constant individual difference that affects behavioral aggression across contexts (Anderson \& Dill, 2000; Canary et al., 1998; Dula \& Ballard, 2003; Eron \& Huesmann, 1990; Huesmann et al., in press). Dispositional aggression is measured using questionnaires such as the Interpersonal Behavior Survey (Mauger \& Adkinson, 1993) and the Aggression Questionnaire (Buss \& Warren, 2000). These instruments survey various facets of aggression, including thoughts, feelings, and reactivity related to physical aggression, verbal aggression, hostility, and anger.

Research indicates a relationship between measures of dispositional aggression and behavioral aggression among adolescents and adults across contexts (Coles, Greene, \& Braithwaite, 2002; Driscoll, Jarman, \& Yankeelov, 1994; Dula \& Ballard, 2003; Vance, Fernandez, \& Biber, 1998). For example, those who score higher on measures of dispositional aggression are more likely to engage in driver aggression (Deffenbacher, Lynch, Deffenbacher, \& Oetting, 2001; Dula \& Ballard, 2003). Those high in dispositional aggression are also more behaviorally aggressive after exposure to violent video games (Dill et al., 1997) and violent movies (Kiewitz \& Weaver, 2001). Finally, among adult samples, those high in dispositional aggression are more likely to perpetrate spousal abuse (Schumacher, Feldbau-Kohn, Slep, \& Heyman, 2001) and workplace violence (Douglas \& Martinko, 2001; Neuman \& Baron, 1998). Less is known about such correlations among children and adolescents, but children who perpetrate school aggression are likely to have a history of aggression and/or being bullied (Speaker \& Petersen, 2000; Vance et al., 1998) and are more likely to have friends who are aggressive (Coie et al., 1999; Dodge, Coie, Pettit, \& Price, 1990; Minden, Henry, Tolan, \& Gorman-Smith, 2000). Further, children who are aggressive in mid-to-late childhood are likely to be aggressive in adolescence (Séguin, Arseneault, Boulerice, Harden, \& Tremblay, 2002). Perseveration of aggression is related to having a difficult temperament, which is linked to dispositional aggression (Anderson \& Bushman, 2001a; 2001b; Séguin et al, 2002). 
School-related violence has declined in recent years, and children are more likely to be harmed while away from school than while at school (Mulvey \& Cauffman, 2001; Indicators..., 2001). Even so, school aggression is of concern across cultures, as evidenced by research in Canada (Carter \& Stewin, 1999), Finland (Olafsen \& Viemeroe, 2000), France (Mallet \& Paty, 1999), Germany (Martin, 2000), Turkey (Hatipoglu-Suemer \& Aydin, 1999), and the United States (Centers for Disease Control and Prevention, 1997; the National School Safety Center 2000; Sourcebook..., 1999). School aggression can be physical (e.g., fighting, hair pulling), verbal (e.g., threats, insults), or relational (e.g., alienation, gossip). We chose to focus on physical and serious verbal aggression, as these behaviors were recorded in school records. It should be noted, however, that relational aggression often results in more serious aggressive incidents (Olafsen \& Viemeroe, 2000).

\section{STATEMENT OF PROBLEM AND HYPOTHESES}

Given the association between dispositional aggression and behavioral aggression described in the literature review, we expected that dispositional aggression, measured using the general aggression subscale of the Interpersonal Behavior Survey, would account for a significant amount of the variance in boys' records of school aggression. Although it is not central to the thesis, based on past research (Brooks-Gunn \& Duncan, 1997) we also expected that factors related to socioeconomic status (e.g., parental education, family income) would account for a significant portion of the variance in boys' school aggression. Further, due to findings regarding the stability and perseveration of aggression into adolescence (Eron, 1987; Eron \& Huesmann, 1990; Huesmann et al., 1984; Huesmann et al., in press; Loeber \& Hay, 1997; Séguin et al., 2002), we expected that a minority of boys would account for a majority of aggressive incidents. Thus, in addition to fleshing out our understanding of dispositional aggression, these data add to our knowledge of school aggression, in terms of both the factors related to school aggression and descriptive data regarding the incidence of school aggression.

\section{METHOD}

\section{Participants}

Participants included 100 adolescent males from a suburban Charlotte, NC, middle school (grades 6-8). Most ( $n=69)$ of the participants were White, the remainder $(n=31)$ were Black; this is representative of the school and community (Population Estimates..., 1998). Participants ranged in age from 11 to 15 years $(\mathrm{M}=12.7)$. Participant SES, as evidenced by parental education, ranged from lower class to upper middle class. The working class students were bused from "inner city" Charlotte to an upper middle class neighborhood for school. Participants received a small gift (i.e., candy, toy) for their participation in the study.

\section{Measures}

A demographic questionnaire, completed by the parent or guardian, was used to gather students' age, grade level, self-reported ethnicity, annual family income, marital status of parents, parents' level of education, and the amount of time the student had attended the middle school.

Each participant's student record was used to code administrative reports of school aggression. School administrators used a standard coding scheme, developed by administrators based on past aggressive incidents, to record 17 categories of aggression into student records-fist fight, two-on-one fight, hit a teacher/staff member, shoved a student in anger, shoved a teacher/staff member in anger, pushed someone out of the way (instrumental, not hostile), threw an object at a student, verbal harassment of a student, took property from a student via force, took property from a student via intimidation, kicked a student, bit a student, fought a student with a weapon, made fun of a student's looks, threatened a student with physical harm, threatened a teacher with physical harm, and brought a gun/knife to school. For each of these categories of aggression, the administrator had recorded the number of times each student had engaged in the behavior. None of the boys 
had been cited for bringing a gun or knife to school, so this item was not used in the analyses. For each student, the number of recorded instances of each of the 16 remaining items was summed for a total school aggression score. Four behaviors (verbal harassment, threatened student, threatened teacher, made fun of student) were used to calculate a verbal aggression score, and the remaining 12 behaviors were totaled to calculate a physical aggression score.

The measure of dispositional aggression was drawn from the 34-item, self-report Interpersonal Behavior Survey-Short Form (IBS; Mauger \& Adkinson, 1993). The IBS, so labeled to avoid demand characteristics, includes subscales of general assertiveness and denial, in addition to the general aggressiveness subscale. Only the general aggressiveness subscale was used in this study. This subscale measures aggressive feelings and cognitions (e.g., It is never all right to harm someone else.; There are times I would enjoy hurting people I love.; I enjoy making people angry). Each item is rated on a Likert-type scale from 1 (not at all like me) to 5 (completely like me). Raw scores were converted to T-scores for use in the analyses. The IBS general aggressiveness subscale has excellent test-retest reliability ( $r=.81$ for a 10 -wk. interval) and internal consistency ( $\alpha=.73)$ and is moderately correlated with the subscales of the Buss-Durkee Hostility Inventory, which include hostility $(r=.57)$, indirect hostility $(r=.50)$ and assault $(r=.38)$ scales (Mauger \& Adkinson, 1993).

\section{Procedure}

Parents of each male student $(\mathrm{N}=445)$ at the middle school were sent a packet containing a cover letter/consent form that explained the study and described the measures, a demographic form, a release for school records, and a self-addressed, stamped envelope to return the forms. One hundred parents (22\% total; $27 \%$ of parents of White boys and $14 \%$ of parents of Black boys) returned the forms, giving permission for their sons to participate. This is a lower rate of return than typical (33-44\%) for school-based surveys (Gillig \& Zimmer, 1986), but is a higher return rate than other researchers have obtained in the same area (K. D.

Michael, personal communication, July 28, 2002). Follow-up calls made by the second author indicated that many of the children and parents from the school had recently participated in a lengthy survey study and did not want to participate in another study so soon. Thus, non-participation in the study seemed to be related to "study fatigue," rather than to potentially confounding variables such as temperament, ethnicity, or age. After their parents gave consent, participants were scheduled to complete the study. Students were run in small groups (5-8) in the school's media center. They were seated apart for privacy. Each participant signed an informed assent and completed the IBS. They were asked not to discuss the questions or their answers with their peers. The second author monitored the students during each session. The procedure lasted $30 \mathrm{~min}$. After completing the forms, each participant was debriefed and given his choice of candy or a small toy.

\section{RESULTS}

\section{Descriptive Statistics}

Of the 100 boys, a majority $(n=58)$ had an administrative record of aggressive behavior at school. The most common aggressive behaviors, with number of infractions reported parenthetically, were fist fights $(\mathrm{n}=30)$, shoving another student in anger $(n=27)$, pushing someone out of the way $(n=20)$, throwing an object at another student $(\mathrm{n}=19)$, verbal harassment $(\mathrm{n}=15)$, taking property from another student via intimidation $(\mathrm{n}=$ 14), and kicking another student $(n=12)$. Aggression directed at teachers, such as hitting $(n=7)$, shoving $(n=$ $1)$, and threats $(n=2)$ was uncommon. Biting $(n=2)$ and threatening students $(n=6)$ were also uncommon.

The total number of recorded acts of school aggression was 402. The overall mean for aggressive acts while attending the middle school was $4.02(\mathrm{sd}=5.64)$. When the students with no infractions $(\mathrm{n}=42)$ were removed from the equation, the boys with a history of school aggression $(n=58)$ had a mean of $6.93(\mathrm{sd}=$ 5.89) aggressive acts. Several of these boys $(n=13)$ had only one citation for aggression, but many $(n=45)$ 
were repeat offenders. Seventeen of the boys had 5 to 10 citations for aggressive behavior at school, and an additional 14 boys had more than 10 citations for aggression. Thus, a minority (31\%) of the boys perpetrated most (86\%) of the administratively recorded aggression.

\section{Mean Comparisons}

A median split of administrative citations for aggression was used to divide the boys into high and low school aggression groups. A t-test was performed, with level of school aggression as the between subjects factor and IBS aggressiveness scores as the dependent measure. The t-test was significant, $t(98)=6.17, p<.001$. Boys high in school aggression $(M=40.00$, sd $=5.86)$ had significantly higher scores on the IBS aggression score than did boys low in school aggression $(M=33.89$, $\mathrm{sd}=4.01)$. We also used t-tests to see if ethnic background was related to mean differences on the variables (i.e., school records of total, verbal, and physical aggression, and IBS aggression sub-scores). There were no ethnic differences (all ps >.05). Ethnic differences in each aggressive behavior were examined using t-tests; a was set at $\mathrm{p}<.01$ to correct for family-wise error. There were no ethnic differences (all ps $<.03$ ), so we collapsed the data across ethnicity for the analyses.

\section{Correlational and Regression Analyses}

Partial correlations were performed to examine the relationship between IBS aggression scores and administrative records of aggression. Length of time enrolled in the middle school served as a covariate. There were strong, significant positive correlations between IBS aggression scores and administratively recorded verbal aggression, physical aggression, and total aggression (see Table 1).

Regression analyses were performed with administrative records of overall school aggression, verbal aggression, and physical aggression as the dependent factors. Length of time enrolled in the middle school was entered first into each equation. IBS general aggression scores and demographic variables that have been correlated with aggression (age, family income, and parents' education) were entered as predictor variables in a stepwise fashion. See Tables 2, 3, and 4 for additional statistics.

With regard to total school records of aggression, $36 \%$ of the variance was accounted for. Length of time enrolled accounted for $3 \%$ of the variance, IBS aggression scores accounted for $28 \%$ of the variance, and age accounted for $5 \%$ of the variance. In terms of verbal aggression, only $15 \%$ of the variance was accounted for. IBS aggression scores accounted for $10 \%$ of the variance and family income accounted for $5 \%$ of the variance. Finally, 36\% of the variance in physical aggression was accounted for. Length of time enrolled accounted for $4 \%$ of the variance, IBS aggression scores accounted for $27 \%$ of the variance, and age accounted for $5 \%$ of the variance. The remainder of the factors did not account for a significant portion of the variance in school aggression.

\section{DISCUSSION}

The hypotheses that (a) dispositional aggression would predict school aggression and (b) a minority of boys would account for a majority of school aggression were supported. Rates of administratively documented school aggression were strongly, positively correlated to levels of dispositional aggression. Dispositional aggression was a better predictor of behavioral aggression than demographic variables such as age, ethnicity, and socioeconomic status. These results add to the evidence that dispositional aggression predicts aggressive behavior across a wide range of contexts.

A majority of the boys sampled had engaged in at least one act of school aggression. Of those who had perpetrated school aggression, most were repeat offenders, displaying the sort of perseveration described by Séguin et al. (2002). Thus, as expected, a minority of the boys were culpable for most of the aggression 
recorded at this school. Since most boys who perpetrate school aggression do not desist from this behavior during the middle school years, a past history of school aggression may be the best predictor for subsequent school aggression, including bullying (Pellegrini \& Bartini, 2000; Solberg \& Olweus, 2003).

However, the aggression among these boys was relatively mild. Fist fights, a common method of settling disputes among young adolescent boys (Baron, Forde, \& Kennedy, 2001; Lindeman, Harakka, \& KeltikangasJaervinen, 1997) were the most frequent form of school aggression recorded for this sample. Other minor acts of aggression, such as pushing and shoving, were also common. However, more serious forms of aggression (e.g., biting, fighting with a non-lethal weapon) were uncommon and there was no serious violence (e.g., stabbings, shootings) among this sample. These results are consistent with Mulvey and Cauffman (2001), who contend that serious acts of violence are rare at school and, consequently, difficult to predict.

While it may be true that specific incidents of school aggression and school violence are difficult to predict, our results indicate that both dispositional aggression and past history of school aggression predicted school aggression. Dispositional aggression was a better predictor of physical aggression than verbal aggression. Thus, while measures of dispositional aggression would not be useful in predicting specific incidents of aggression, they could be useful in predicting which boys are at greater risk for engaging in physical aggression at school. If coupled with data regarding prior aggression, measures of dispositional aggression could be useful for screening adolescents who might benefit from intervention aimed at reducing dispositional and behavioral aggression. School- or community-based interventions for aggression could include cognitive therapies (e.g., Cavell \& Hughes, 2000; Larson, Calamari, West, \& Frevert, 1998; Robinson, Smith, Miller, \& Brownell, 1999), bibliotherapy (Shectman, 1999; 2000), and/or martial arts training (Lamarre \& Nosanchuk, 1999; Skelton, Glynn, \& Berta, 1991).

At this point, dispositional aggression is not well understood. Further research is needed to examine the factors related to the development of dispositional aggression (e.g., temperament, parenting, media exposure) and to tease apart the physiological, cognitive, and emotional bases of individual differences in behavioral aggression. Some recently proposed models, including the General Aggression Model (Anderson \& Bushman, 2001a; 2001b) are useful in conceptualizing the components of aggression, but are inadequate to predict or explain specific incidents of aggression.

The nature of the data used in this study has both benefits and limitations. On the positive side, the data were collected by school administrators in context and in a standard fashion. However, a potential limitation arises from the use of a pre-established method of recording school aggression into school records. That is, the data are based on a collection of behaviors that was set up by school administrators, rather than a system that was derived from the literature. Conspicuously absent from the coding scheme was relational aggression, which aims to harm others socially (e.g., Crick, 1995), perhaps because it is difficult to observe and report social aggression. Further, relational aggression has not been as great a concern to school administrators as physical and verbal aggression.

It is likely that administrators are not privy to much of the aggression that occurs at school. Aggression is likely perpetrated most often out of the view of administrators, and victims may be hesitant to report such incidents, particularly if they were threatened further harm by the perpetrator (Bendixon \& Olweus, 1999; Pellegrini \& Bartini, 2000). Relational aggression would be even more difficult to observe and intervene in than physical and verbal aggression. However, as boys with a history of aggression are more likely to perseverate in this behavior, they could be monitored more closely by school administrators. Closer supervision might prevent many aggressive incidents and/or ensure that fewer aggressive incidents would go unreported.

The biggest shortcoming of the study is the relatively low response rate-only $22 \%$ of parents returned consent forms to allow their sons to participate. The sample was representative of the school in terms of ethnicity and other demographic factors. However, there is no way to evaluate if this subset of students differs in their level of aggression from those who did not participate. 
In summary, mild to moderate aggression is common among middle school boys with high levels of dispositional aggression. Dispositional aggression does account for a substantial amount of variance in aggressive behavior at school. Boys who engage in aggressive behavior at school are likely to be repeat offenders, indicating that both screening for dispositional aggression and the individual's history of school aggression could be used to identify boys who might benefit from intervention. Indeed, given that not all aggressive incidents are reported, students with high levels of dispositional aggression might be targeted for preventative intervention, even in the absence of a history of reported school aggression.

\section{REFERENCES}

Anderson, C. A., \& Bushman, B. J. (2001a). Effects of violent video games on aggressive behavior, aggressive cognition, aggressive affect, physiological arousal, and prosocial behavior: A meta-analytic review of the scientific literature. Psychological Science, 12, 353-359.

Anderson, C. A., \& Bushman, B. J. (2001b). Human aggression. Annual Review of Psychology, 53, 27-51.

Anderson, C. A., \& Dill, K. E. (2000). Video games and aggressive thoughts, feelings, and behavior in the laboratory and in life. Journal of Personality and Social Psychology, 78, 772-790.

Baron, S. W., Forde, D. R., \& Kennedy, L. W. (2001). Rough justice: Street youth and violence. Journal of Interpersonal Violence, 16, 662-678.

Bendixon, M., \& Olweus, D. (1999). Measurement of antisocial behaviour in early adolescence and adolescence: Psychometric properties and substantive findings. Criminal Behaviour and Mental Health, 9, 323-354.

Berkowitz, L. (1998a). Frustration-aggression hypothesis: Examination and reformulation. Psychological Bulletin, 106, 59-73.

Berkowitz, L. (1998b). Affective aggression: The role of stress, pain, and negative affect. In R. G. Geen, \& E. Donnerstein (Eds.) Human aggression: Theories, research, and implications for social policy (pp. 49-

72). San Diego, CA: Academic Press.

Brooks-Gunn, J., \& Duncan, G. J. (1997). The effects of poverty on children. The Future of Children, Summer/Fall, 55-71.

Bushman, B. J. (1995). Moderating role of trait aggressiveness in the effects of violent media on aggression. Journal of Personality and Social Psychology, 69, 950-960.

Bushman, B. J. (1996). Individual differences in the extent and development of aggressive cognitiveassociative

networks. Personality and Social Psychology Bulletin, 22, 811-819.

Buss, A. H., \& Warren, W. L. (2000). Aggression questionnaire. Los Angeles, CA: Western Psychological Services.

Canary, D. J., Spiztberg, B. H., \& Semic, B. A. (1998). The experience and expression of anger in interpersonal settings. In P. A. Anderson, \& L. K. Guerrero (Eds.) Handbook of communication and emotion: Research, theory, applications, and contexts (pp. 189-213). San Diego: Academic Press.

Carlo, G., \& Roesch, S. C. (1998). The multiplicative relations of parenting and temperament to prosocial and antisocial behaviors in adolescence. Journal of Early Adolescence, 18, 266-290. 
Carter, S. P., \& Stewin, L. L. (1999). School violence in the Canadian context: An overview and model for intervention. International Journal for the Advancement of Counseling, 21, 267-277.

Cavell, T. A., \& Hughes, J. N. (2000). Secondary prevention as context for assessing change processes in aggressive children. Journal of Social Psychology, 38, 199-235.

Centers for Disease Control and Prevention. (1997). Rates of homicide, suicide, and firearm-related death among children—26 industrialized countries. Mortality and Morbidity Weekly Report, 46, 101-105.

Coie, J. D., Cillessen, A. H. N., Dodge, K. A., Hubbard, J. A., Schwartz, D., \& Lemerise, E. A. (1999). It takes two to fight: A test of relational factors and a method for assessing aggressive dyads.

Developmental Psychology, 35, 1179-1188.

Coles, C. J., Greene, A. F., \& Braithwaite, H. O. (2002). The relationship between personality, anger expression, and perceived family control among incarcerated male juveniles. Adolescence, 37, 395-409.

Crick, N. R. (1995). Relational aggression: The role of intent attributions, feelings of distress, and provocation type. Development and Psychopathology, 7, 313-322.

Deffenbacher, J. L., Lynch, R. S., Deffenbacher, D. M., \& Oetting, E. R. (2001). Further evidence of reliability and validity for the Driving Anger Expression Inventory. Psychological Reports, 89, 535-540.

Dill, K. E., Anderson, C. A., Anderson, K. B., \& Deuser, W. E. (1997). Effects of aggressive personality on social expectations and social perceptions. Journal of Research in Personality, 31, 272-292.

Dodge, K. A., Coie, J. D., Pettit, G. S., \& Price, J. M. (1990). Peer status and aggression in boy’s groups: Developmental and contextual analysis. Child Development, 61, 1289-1309.

Douglas, S. C., \& Martinko, M. J. (2001). Exploring the role of individual differences in the prediction of workplace aggression. Journal of Applied Social Psychology, 86, 547-559.

Driscoll, J. M., Jarman, B. J., \& Yankeelov, P. A. (1994). Effects of a person’s history of aggression on attributions of affect to aggressors. Journal of Social Behavior and Personality, 9, 685-700.

Dula, C. S., \& Ballard, M. E. (2003). Correlates of aggressive, risky, and emotional driving. Journal of Applied Social Psychology, 33, 263-282.

Eron, L. D. (1987). The development of aggressive behavior from the perspective of a developing behaviorism.

American Psychologist, 42, 435-442.

Eron, L. D., \& Huesmann, L. R. (1990). The stability of aggressive behavior-even unto the third generation. In M. Lewis \& S. M. Miller (Eds.), Handbook of developmental psychopathology: Perspectives in developmental psychology (pp. 147-156). New York: Plenum.

Geen, R. G., (1998). Processes and personal variables in affective aggression. In R. G. Geen \& E. Donnerstein (Eds.), Human aggression: Theories, research, and implications for social policy (pp. 1-21). San Diego, CA: Academic Press.

Gillig, S., \& Zimmer, J. W. (1986). Survey return rate and size of school district. Psychological Reports, 58, 381-382. 
Hatipoglu-Suemer, Z., \& Aydin, G. (1999). Incidence of violence in Turkish schools. A review. International Journal for the Advancement of Counseling, 21, 335-347.

Huesmann, L. R. (1994). Aggressive behavior: Current perspectives. New York, NY: Plenum Press.

Huesmann, L. R., Eron, L. D., Lefkowitz, M. M., \& Walder, L. O. (1984). Stability of aggression over time and generations. Developmental Psychology, 20, 1120-1134.

Huesmann, L. R., Moise-Titus, J., Podolski, C. P., \& Eron, L. D. (2003). Longitudinal relations between children's exposure to TV violence and their aggressive and violent behavior in young adulthood: 19771992. Developmental Psychology, 39, 201-221.

Indicators of School Crime and Safety, 2001 (2001). Retrieved December 17, 2001, from http://nces.ed.gov/pubs2002/crime2001.

Keiwitz, C., \& Weaver, J. B. III. (2001). Trait aggressiveness, media violence, and perceptions of interpersonal conflict. Personality and Individual Differences, 31, 821-835.

Lamarre, B. W., \& Nosanchuk, T. A. (1999). Judo-the gentle way: A replication of studies on martial arts and aggression. Perceptual and Motor Skills, 88, 992-996.

Larson, J. D., Calamari, J. E., West, J. G., \& Frevert, T. A. (1998). Aggression management with disruptive adolescents in a residential setting: Integration of a cognitive-behavioral component. Residential Treatment for Children and Youth, 15, 1-9.

Lindeman, M., Harakka, T., \& Keltikangas-Jaervinen, L. (1997). Age and gender differences in adolescents' reactions to conflict situations: Aggression, prosociality, and withdrawal. Journal of Youth and Adolescence, 26, 339-351.

Loeber, R., \& Hay, D. (1997). Key issues in the development of aggression and violence from childhood to early adulthood. Annual Review of Psychology, 48, 371-410.

Mallet, P., \& Paty, B. (1999). How French counsellors treat school violence: An adult-centered approach. International Journal for the Advancement of Counseling, 21, 279-300.

Martin, L. R. (2000). Violence in German Schools: What school counsellors can do. International Journal for the Advancement of Counseling, 21, 301-313.

Mauger, P. A., \& Adkinson, D. R. (1993). Interpersonal Behavior Survey manual. Los Angeles, CA. Western Psychological Services, Inc.

Minden, J., Henry, D. B., Tolan, P. H., \& Gorman-Smith, D. (2000). Urban boys’ social networks and school violence. Professional School Counseling, 4, 95-104.

Mulvey, E. P., \& Cauffman, E. (2001). The inherent limits of predicting school violence. American Psychologist, 56, 797-802.

National School Safety Center. (2000). Report on school associated violent deaths. Retrieved December 17, 2001, from http://www.nssc1.org/savd.

Neuman, J. H., \& Baron, R. A. (1998). Workplace violence and workplace aggression: Evidence concerning specific forms, potential causes, and preferred targets. Journal of Management, 24, 391-419. 
Olafsen, R. N., \& Viemeroe, V. (2000). Bully/victim problems and coping with stressing school among 10- to 12-year-old pupils in Aland, Finland. Aggressive Behavior, 26, 57-65.

Pellegrini, A. D., \& Bartini, M. (2000). A longitudinal study of bullying, victimization, and peer affiliation during the transition from primary school to middle school. American Education Research Journal, 37, 699-725.

Population Estimates by Age, Sex, and Race-Mecklenburg County, North Carolina. (1998). Retrieved December 17, 2001, from http://www.govinfo.library.orst.edu/cgi-bin/pe-list?map=01-119.ncc.

Robinson, T. R., Smith, S. W., Miller, M. D., \& Brownell, M. T. (1999). Cognitive behavior modification of hyperactivity-impulsivity and aggression: A meta-analysis of school-based studies. Journal of Educational Psychology, 91, 195-203.

Schectman, Z. (2000). An innovative intervention for treatment of child and adolescent aggression: An outcome study. Psychology in the Schools, 37, 157-167.

Schectman, Z. (1999). Bibliotherapy: An indirect approach to treatment of childhood aggression. Child Psychiatry and Human Development, 30, 39-53.

Schumacher, J. A., Feldbau-Kohn, S., Slep, A. M. S., \& Heyman, R. E. (2001). Risk factors for male-tofemale partner physical abuse. Aggression and Violent Behavior, 6, 281-302.

Séguin, J. R., Arseneault, L., Boulerice, B., Harden, P. W., \& Tremblay, R. E. (2002). Response perseveration in adolescent boys with stable and unstable histories of physical aggression: The role of underlying processes. Journal of Child Psychology and Psychiatry, 43, 481-494.

Skelton, D. L., Glynn, M. A., \& Berta, S. M. (1991). Aggressive behavior as a function of tae-kwon-do ranking. Perceptual and Motor Skills, 72, 179-182.

Solberg, M. E., \& Olweus, D. (2003). Prevalence estimation of school bullying with the Olweus Bully/Victim Questionnaire. Aggressive Behavior, 29, 239-268.

Sourcebook for Criminal Justice Statistics. (1999). Tables 3.44; 3.46; 3.64 \& 3.65. Retrieved December 17, 2001, from http://www.albany.edu/sourcebook.

Speaker, K. M., \& Petersen, G. J. (2000). School violence and adolescent suicide: Strategies for effective intervention. Educational Review, 52, 65-73.

Vance, J. E., Fernandez, G., \& Biber, M. (1998). Educational progress in a population of youth with aggression and emotional disturbance: The role of risk and protective factors. Journal of Emotional and Behavioral Disorders, 6, 214-221. 


\section{FIGURES AND TABLES}

TABLE 1. Partial Correlations Between Dispositional and School Aggression

\begin{tabular}{lllll}
\hline & IBS & Verbal & Physical & Total \\
& Aggresssion & Aggression & Aggression & Aggression \\
\cline { 2 - 5 } & & & & \\
IBS Aggression & $\ldots .-31^{*}$ & $.54^{* *}$ & $.54^{* *}$ \\
Verbal Aggression & $.31^{*}$ & $\ldots$ & $.48^{* *}$ & $.64^{* *}$ \\
Physical Aggresssion & $.54^{* *}$ & $.48^{* *}$ & $\ldots$ & $.98^{* *}$ \\
Total Aggression & $.54^{* *}$ & $.64^{* *}$ & $.98^{* *}$ & $\ldots$ \\
\end{tabular}

${ }^{*} \mathrm{n}<.01,{ }^{*} \mathrm{n}<.001$; Years at the middle school served as a covariate.

TABLE 2. Summary of Predictor Variables Regressed onto School Records of Overall Aggression

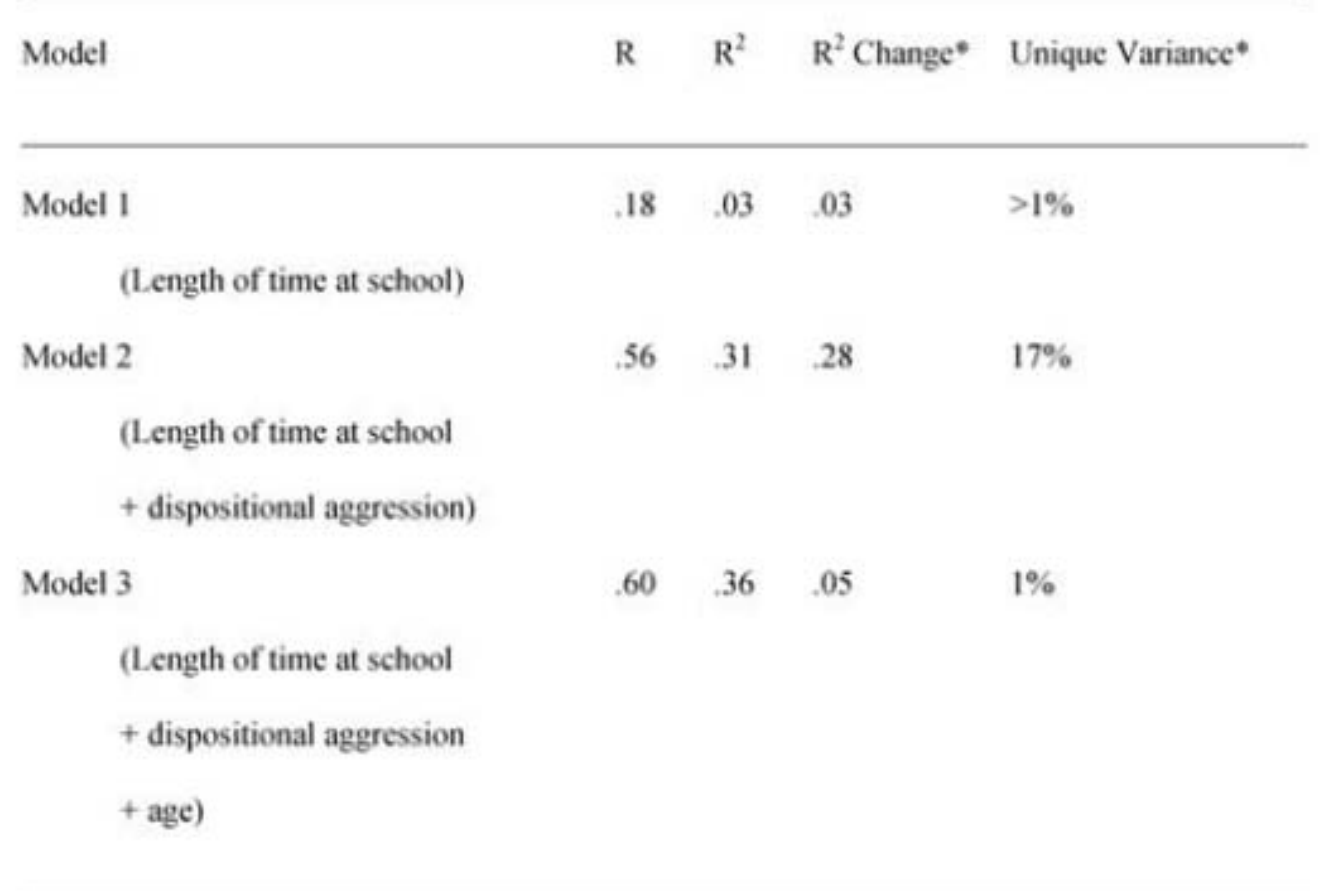

$-R^{2}$ change and unique variance of the predictor variable added at each step. 
TABLE 3. Summary of Predictor Variables Regressed onto School Records of Verbal Aggression

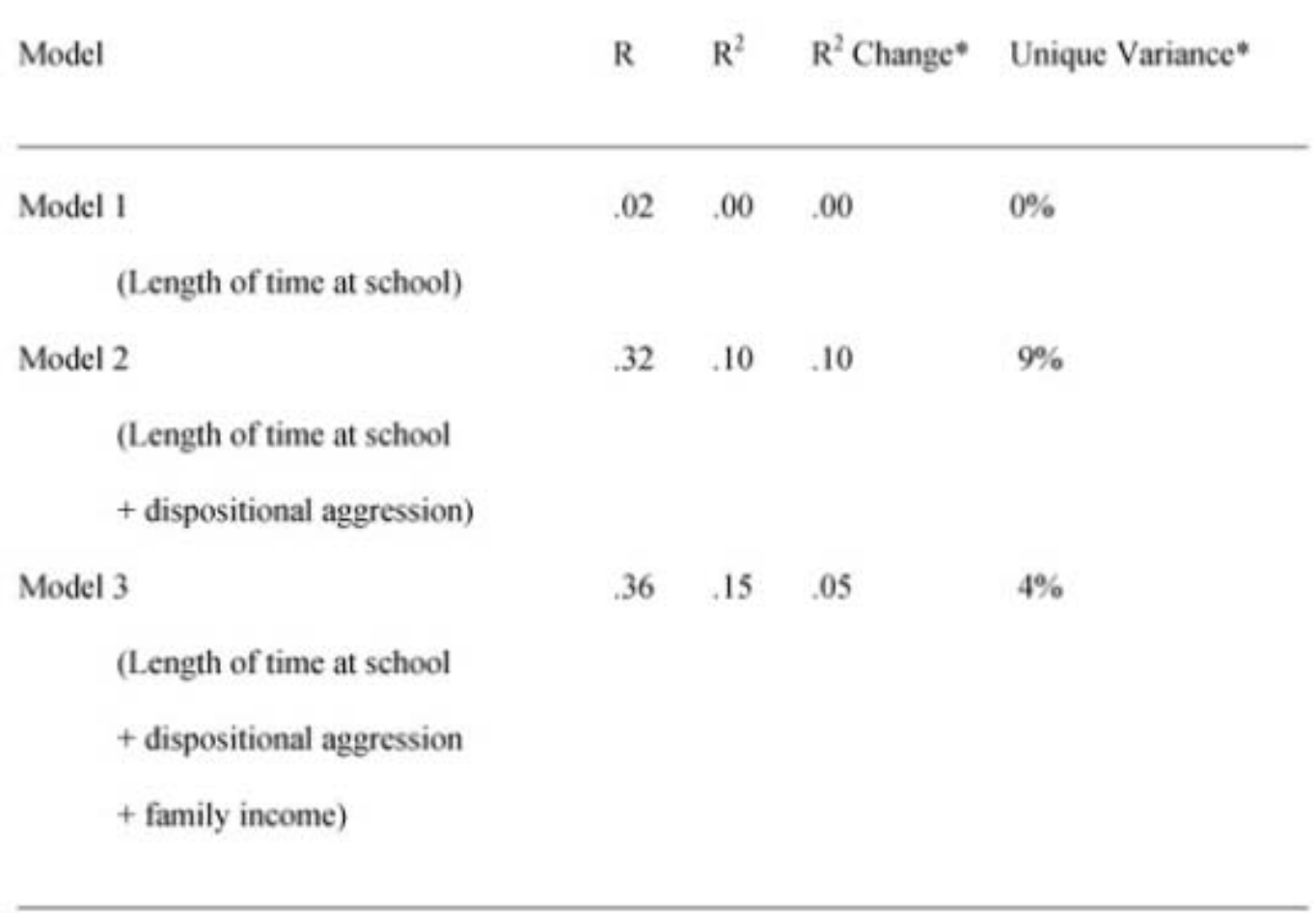

${ }^{*} \mathrm{R}^{2}$ change and unique variance of the predictor variable added at each step. 
TABLE 4. Summary of Predictor Variables Regressed onto School Records of Physical Aggression

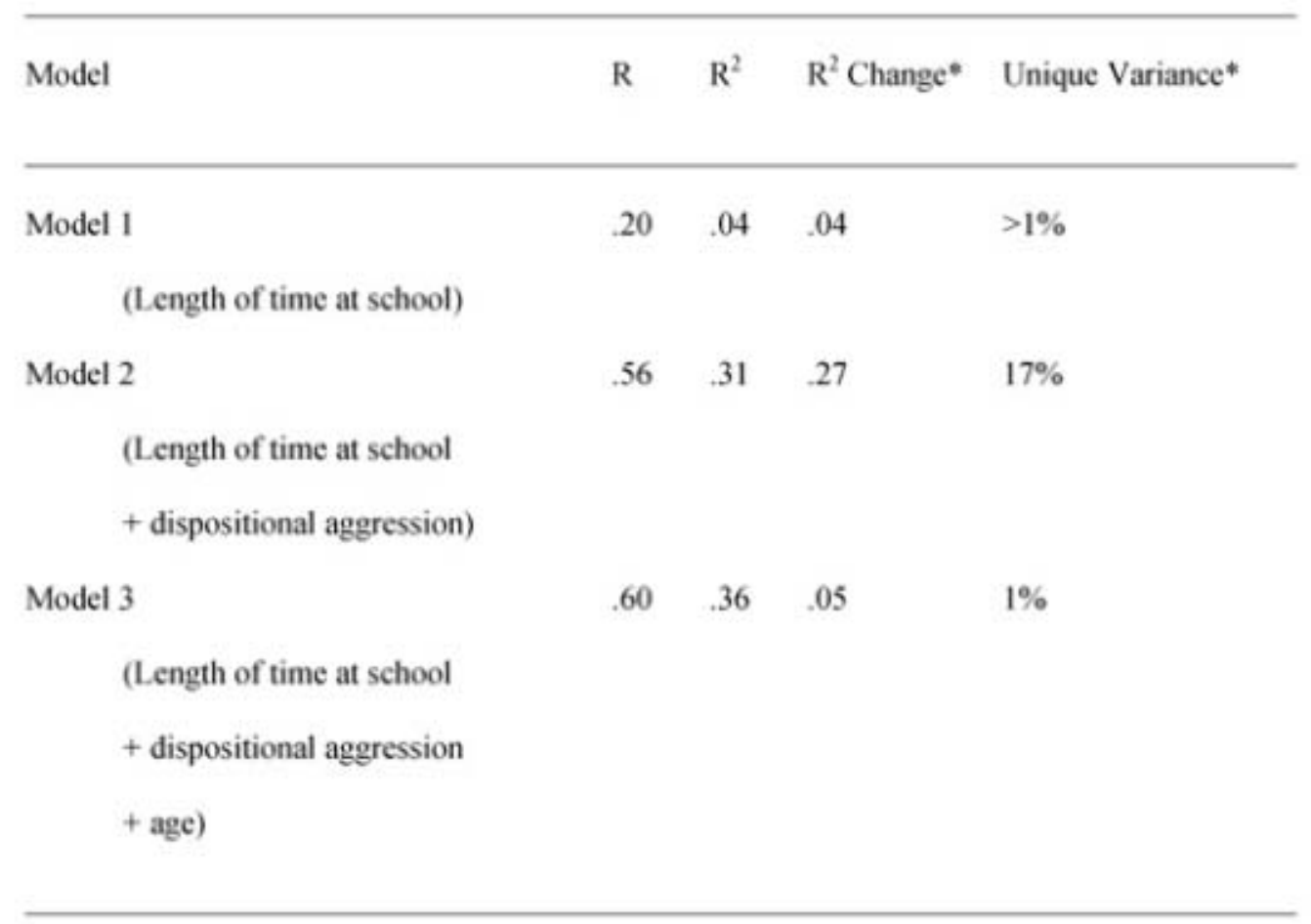

$-R^{2}$ change and unique variance of the predictor variable added at each step. 